
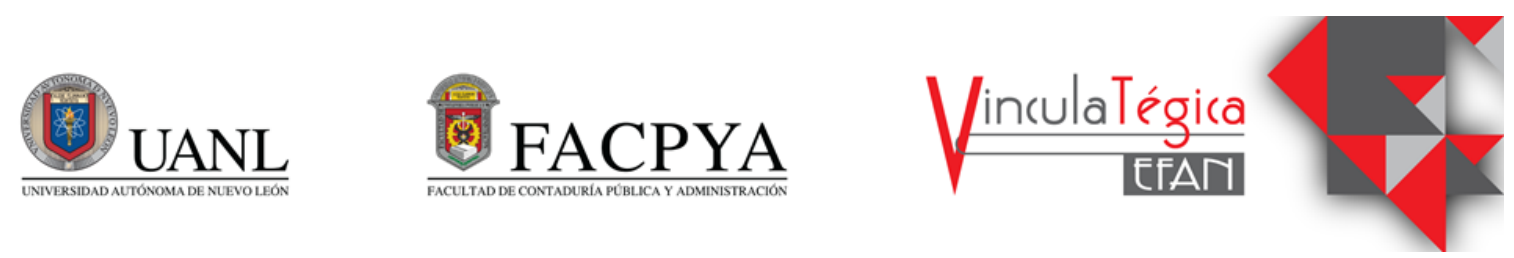

\title{
Retos en la administración de recursos humanos ante pandemia Covid-19 en organizaciones de Nuevo León (México)
}

\author{
Nury Margarita Leal Rendón ${ }^{1}$, María de los Ángeles Martínez Mercado² \\ y Daniela del Carmen Bacre Guzmán ${ }^{3}$
}

\begin{abstract}
'Universidad Autónoma de Nuevo León, Facultad de Ciencias Químicas, Monterrey Nuevo León, México, nury.leal@gmail.com, Av. Universidad S/N, Ciudad Universitaria, (+52) 8183294000 Ext. 6321.

2Universidad Autónoma de Nuevo León, Facultad de Ciencias Químicas, Monterrey Nuevo León, México, maría.mtzm@yahoo.com.mx, Av. Universidad S/N, Ciudad Universitaria, (+52) 8183294000 Ext. 6286.

Universidad Autónoma de Nuevo León, Facultad de Ciencias Químicas, Monterrey Nuevo León, México, dbacre@gmail.com, Av. Universidad S/N, Ciudad Universitaria, (+52) 8183294000 Ext. 6286.
\end{abstract}

Información del artículo revisado por pares

Fecha de aceptación: junio-2021

Fecha de publicación en línea: diciembre-2021

DOI: https://doi.org/10.29105/vtga7.2-23

\section{Resumen}

La presente investigación da a conocer los retos y nuevas prácticas a los que se enfrenta la administración del recurso humano causadas tras la pandemia COVID-19 en organizaciones del estado de Nuevo León, mismas que han permitido adaptarse a las condiciones actuales del entorno. El método que se utilizo es de carácter cualitativa con alcance descriptivo.

Palabras clave: administración, Covid-19, recursos humanos.

\section{INTRODUCCIÓN}

\subsection{El problema general}

Como consecuencia de la pandemia provocada por el Coronavirus (Covid-19), las empresas y las economías se vieron impactadas de manera significativa por la velocidad en que se propago el virus. Todos nos enfrentamos a una crisis sin precedentes, cambiando de manera radical el modo de trabajar. Los retos a los que se han afrontado el departamento de Recursos Humanos durante la pandemia los han llevado a estilos de trabajo que probablemente se seguirán utilizando en un futuro entrando a una nueva normalidad post

\begin{abstract}
This research reveals the challenges and new practices faced by the human resource administration caused by the COVID-19 pandemic in Nuevo León state organizations, which have made it possible to adapt to the current environmental conditions. A qualitative method with a descriptive scope is used.
\end{abstract}

Keywords: administration, Covid-19, human resources. JEL: J24, J81

pandemia.

Por este motivo la presente investigación explora acerca las practicas que las empresas han implementado en sus departamentos de recursos humanos ante el COVID-19, para poder adaptarse a las nuevas formas de trabajo que nos obliga el entorno.

\subsection{Objetivo de estudio}

El presente estudio busca conocer las principales practicas implementadas para la administración del recurso humano causados tras la pandemia Covid-19 en organizaciones del estado de Nuevo León. 


\section{MARCO TEÓRICO}

\subsection{COVID- 19}

De acuerdo con la Organización Mundial de la Salud (OMS, 2020), los coronavirus se consideran como una basta parentela de virus que podrían provocar enfermedades en humanos o en animales. Se conoce, en cuanto a los humanos, que algunos coronavirus pueden causar infecciones de tipo respiratorio, como el resfriado común o enfermedades de mayor gravedad, como es el síndrome respiratorio agudo severo (SRAS) o el síndrome respiratorio de Oriente Medio (MERS).

El coronavirus tipo 2, causante del síndrome respiratorio agudo (SRAS-CoV-2), comúnmente conocido como COVID-19, se ha propagado desde China y actualmente es una pandemia que afecta a muchos países de todo el mundo. La Organización Mundial de la Salud, define pandemia como: la difusión en el mundo de una reciente enfermedad. Cuando brota un inédito virus gripal, que se difunde de forma mundial y en donde una gran cantidad de personas carecen de inmunidad ante el nuevo virus, es cuando se genera la pandemia. (La Organización Mundial de la Salud, 2010).

Durante una pandemia hay medidas que todos tenemos que comenzar a adoptar, es importante la participación de empresas, organizaciones sociales y escuelas, junto con el gobierno para ayudar a frenar la propagación de la enfermedad y en muchas ocasiones esto incluye el cierre temporal y/o limitar o cancelar reuniones sociales y públicas, reducir flujo de transporte público, cuarentenas para personas enfermas o que tuvieron contacto con una.

La recuperación de estas situaciones puede ser difícil ya que no ocurre inmediatamente, por lo que es importante que durante la pandemia los negocios puedan subsistir con actividades esenciales y personal limitado, y así mismo estar capacitados para el regreso a las actividades de manera planificada adecuándose a las nuevas condiciones postpandemia.

\subsection{Disposiciones laborales en México ante el Covid-19}

El 28 de febrero de 2020, fue confirmado el primer contagio por COVID-19 en todo el país, tres semanas después, el 16 de marzo de 2020 la Secretaría de Salud anunció la implementación de la Jornada Nacional de Sana Distancia como medida preventiva, en la cual se suspendieron temporalmente actividades no esenciales, y el 1 de junio del mismo año, se reiniciaron las actividades de empresas esenciales adoptando y validando los protocolos de seguridad sanitaria, con una previa aprobación por parte del Instituto Mexicano del Seguro Social. Esta reapertura se controló mediante el semáforo de riesgo epidemiológico por regiones para determinar el nivel de alerta y que tipo de actividades estaban autorizadas para llevarse a cabo.

Durante la suspensión de actividades en México, para las empresas que tuvieron que adoptar nuevas normalidades para continuar funcionando. (Diario Oficial de la Federación. 2020, mayo 29)

De acuerdo con la Secretaría del Trabajo y Previsión Social, Hubo una pérdida de 130,593 puestos, en marzo del 2020, descendiendo un $0.6 \%$, debido a la eventualidad causada por la pandemia que generó el COVID-19 en México, siendo 63,201 empleos fijos y 67,392 de empleo eventual. (Secretaría del Trabajo y Previsión Social, 2020).

Para que las empresas continúen con sus funciones el Instituto Mexicano del Seguro Social en colaboración de la Secretaría de Salud, Secretaría Economía, Secretaría del Trabajo y algunas empresas en México han trabajado para desarrollar un acuerdo por el que se establecen los Lineamientos Técnicos Específicos para la Reapertura de las Actividades Económicas, con el propósito de lograr un retorno a las actividades laborales de manera responsable, tomando medidas preventivas, haciendo uso de listas de comprobación para la identificación de las medidas a implementar, recursos de capacitación CLIMSS, de asesoría por parte del IMSS, y el uso de un mecanismo en línea a través del cual deberán autoevaluar su cumplimiento.

\subsection{Disposiciones Laborales en el Mundo}




\section{ante el Covid-19}

En respuesta al COVID-19 surgieron muchas teorías o ideas de cómo protegerse del virus, actualmente contamos con el conjunto de medidas que fueron confirmadas por la (Organización Mundial de la Salud, 2020) como las más indicadas para atacar el virus, es lógico que estas medidas se pueden ajustar dependiendo de la situación de cada espacio laboral pero la mayoría debe rondar o asimilarse a estas.

Medidas para todos los lugares de trabajo:

- Lavado de manos

- Cuidado e higiene respiratoria

- Distanciamiento físico

- Reducción y administración de viajes relacionados con el trabajo

- Desinfección y limpieza periódica del espacio de trabajo

- Información de riesgos, formación y educación

- Diligencia de personas con COVID19 o sus contactos

Sin embargo, el hecho de que existiera una situación completamente nueva por la que nunca nadie había pasado, tuvo como resultado que los países tuvieran mayor dificultad en la toma de decisiones y dichas decisiones fueron muy diferentes en cada lugar, aquí es donde pudimos notar la capacidad de respuesta de cada país. En muchos de estos se contaba con una cultura de salud muy limpia y siguieron los protocolos de manera muy estricta puesto que entendían la gravedad del asunto, a su vez existieron países que expusieron su falta de capacidad para reaccionar y muchos otros simplemente adaptaron a las medidas de sus países vecinos y fue así como lograron salir adelante. (Organización Internacional del Trabajo 2020)

\subsection{Administración de Recursos Humanos}

Según Dessler y Varela (2011) la administración de recursos humanos alude a las políticas y a las prácticas, que se necesitan en el manejo de las cuestiones vinculadas con las relaciones personales. En cambio, Werther y Davis (2008) definen a la administración de los recursos humanos como la mejora de las aportaciones que hace productivo al personal dentro de una organización, al ser responsables de forma ética, social $y$ estratégica.

Las funciones principales de la administración del personal según Gary Dessler y Ricardo Varela son:

- Reclutar

- Capacitar

- Evaluar

- Remunerar

- Y ofrecer un ambiente seguro

- Con un código de ética

- Trato justo a los empleados ( Dessler y Varela 2011)

La administración de recursos humanos enfrenta desafíos de carácter histórico, externo e interno; nos centraremos en los desafíos externos que son los que se originan en cambios de tipo: económicos, sociales, tecnológicos, ecológicos, políticos, y culturales, y los generados por el sector público (Werther, y Davis (2008), la pandemia la podemos considerar como un nuevo desafío de carácter externo ya que este influye de manera directa en que la organización alcance sus objetivos.

2.6 Funciones importantes que deben realizar los administradores de recursos humanos debido a la pandemia Covid-19 Facilitar el trabajo a distancia sin reducir la productividad y Asegurar la salud y bienestar de las personas

2.6.1 Facilitar el trabajo a distancia sin reducir la productividad

Durante las semanas de confinamiento, el teletrabajo se ha convertido en la mejor oportunidad para hacer compatible la protección frente a la pandemia con el mantenimiento de las actividades productivas. (Peiró \& Soler, 2020), sin embargo, también puede ser un verdadero reto para las empresas y para los empleados, ya que se enfrentan a problemas como son los horarios extenuantes de trabajo, la falta de comunicación y compromiso, problemas técnicos, falta de organización y metas, problemas físicos y emocionales. 
El teletrabajo se define como un método alternativo de trabajo que surge de la mejora en las tecnologías y su uso dentro de las organizaciones (Baruch, 2001). También Baruch afirma que el trabajo a distancia se da en el momento de realizar de forma parcial o totalmente las actividades de trabajo del personal fuera de la ubicación laboral, por lo que utilizan tecnologías de información para poder operar y comunicarse (Baruch, 2001).

En este nuevo contexto, el departamento de recursos humanos son los responsables de facilitar guías para implementar el "teletrabajo, home office o trabajo en casa" de forma exitosa, y de esta manera asegurar el aumento en la productividad y un balance entre los intereses personales y profesionales lo primordial es tener un cambio de mentalidad en empleados y líderes de área, aspecto que incluye la confianza, la flexibilidad y la orientación basada en los objetivos.

"El teletrabajo fue una alternativas que encontraron algunas empresas para hacerle frente a la crisis y poder seguir con su operación, trajo consigo varios retos, dificultades y beneficios, en ultimas los empresarios tendrán que evaluar si siguen con este modelo de trabajo que en algunos casos genera una mayor productividad, bienestar para los trabajadores y permite reducir costos, por otro lado, aquellos que no puedan seguir con el teletrabajo tendrán que adecuar todos sus protocolos y distanciamiento social para que su actividad pueda seguir adelante". (Castellanos, 2020)

2.6.2 Asegurar la salud y bienestar de las personas Uno de los retos a los que se ha tenido que enfrentar durante esta situación es el garantizar la salud física y mental de los trabajadores. Durante las crisis epidémicas se puede incrementar el riesgo de dificultades en la salud mental, causadas por de las disposiciones al restringir la movilidad, el aislamiento, y al disminuir el enlace físico de forma directa. Algunos síntomas de las personas confinadas pueden ser depresión grave y síntomas que se relacionan con el estrés postraumático, aún hayan pasado tres años. (Brooks, y otros, 2020)
En concreto, mantener comunicación ágil desde el primer momento ha sido indispensable para lograr un ambiente de confianza que sirva para minimizar la incertidumbre y el estrés, propios de la situación que se está viviendo. Así mismo, algunas empresas han tenido que establecer protocolos basados en las recomendaciones del gobierno, mantener informados a los empleados acerca de los planes de acción, la situación de la empresa. el estado de salud de los demás empleados y de cómo proceder en caso de presentar síntomas, como identificarlos y con quien comunicarse, por otra parte, para aquellos que tuvieron que seguir trabajando presencialmente, fue primordial la identificación de riesgos y el reforzamiento de las medidas de seguridad y salud.

\section{MÉTODO}

La presente investigación tiene una metodología de carácter cualitativa con alcance descriptivo no inferencial, por lo cual no se planteó una hipótesis, además de un diseño no experimental, para obtener resultados se utilizó el método de la encuesta como herramienta.

El segmento demográfico considerado fueron 50 ejecutivos de Recursos Humanos (gerentes y directores) de empresas del área metropolitana de Monterrey, Nuevo León, México.

Se considero importante el nivel jerárquico de los entrevistados dentro de la organización para que tuvieran el conocimiento y la visión de la planeación estratégica del negocio en cuanto a la administración del personal ante el Covid-19. Las organizaciones que aplicaron son de los siguientes sectores: 28 empresas del giro Industrial, 12 comercial, 4 de salud, 3 de educación, 2 financieras y 1 del sector de transporte.

La encuesta era de 15 preguntas que tenía como fin conocer la siguiente información:

1. Conocimiento general de la organización.

2. Acciones que se realizaron al inicio de la Pandemia.

3. Que acciones se realizaron ante la crisis económica debido a la 
Pandemia.

4. Retos que enfrenta la administración del recurso humano en la Pandemia.

5. Actividades implementadas para el bienestar del trabajador

La confiabilidad del instrumento se basó en la confidencialidad para resguardar el nombre de los participantes y de la empresa. La encuesta se realizó, utilizando la herramienta Microsoft Forms.

\section{RESULTADOS}

Presentaremos los resultados de la encuesta contestada por 50 ejecutivos de diferentes empresas del Nuevo León, la figura 1 nos muestra el tamaño de las empresas encuestadas según su número de trabajadores: 19 empresas tienen menos de 100 empleados esto representa un $38 \%$ de la muestra, 15 empresas tienen más de 1000 empleados es el $30 \%$ de la muestra, 5 empresas tienen entre 501 y 1000 empleados siendo el 10\% de la muestra, 3 empresas tienen entre 251 y 500 empleados que es el $6 \%$ de la muestra, 8 empresas tienen entre 100 y 250 empleados que representa el $16 \%$ de la muestra.

Figura 1. Tamaño de empresas encuestadas según su número de trabajadores.

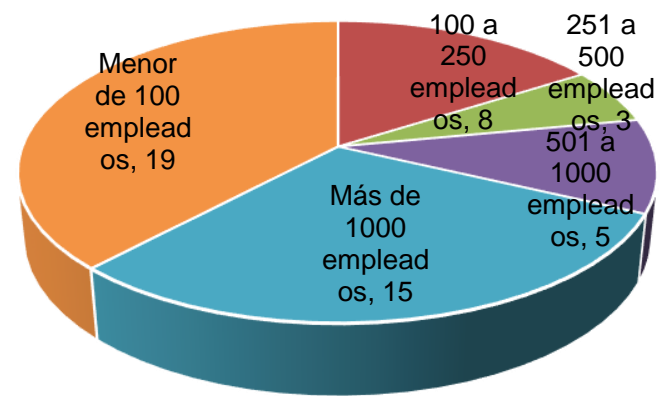

Fuente: Elaboración propia. (Leal N, Martínez M, \& Bacre D 2021)

Obtuvimos que el común denominador de las empresas al inicio de la pandemia fue la Protección de los trabajadores en el lugar de trabajo y el reconocimiento que en realidad no todos los puestos de trabajo deben ser presenciales ya que las tareas que muchos desempeñan se pueden realizar a distancia, fue así como muchas empresas comenzaron a laborar desde sus hogares tratando de sobre llevar una nueva normalidad, la pregunta que

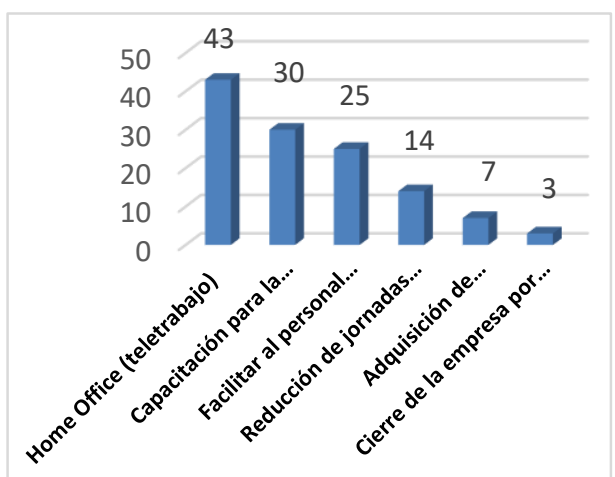

se realizó en la encuesta fue: ¿Qué acciones tomaron al Inicio de la pandemia Covid.19 los administradores de recursos humanos? se obtuvo que 43 empresas optaron porque algunos puestos de sus empresas trabajaran en casa; 30 empresas realizaron capacitación a sus trabajadores para afrontar la nueva forma de trabajo, esta medida fue estratégica para migrar a lo nuevo en corto tiempo, 25 empresas facilitaron al personal herramientas para trabajar en nueva modalidad, 14 empresas redujeron sus jornadas de trabajo esto debido al decremento económico y financiero, por lo que muchas empresas se vieron forzadas a esta disminución de jornadas laborales para no recurrir al despido de trabajadores y dejar sin ingresos al personal.

Figura.2. Afciones al inicio de la pandemia
Esta practica trabajadores $y$ sindicatos ejercicio que raramente las empresas habían realizado; 7 empresas adquirieron infraestructura tecnológica como software, hardware, etc. para que se pudiera realizar el trabajo remoto. 3 empresas fueron cerradas por recomendaciones gubernamentales debido a su giro.

La figura 2. Acciones al inicio de la pandemia, nos muestra un resumen de los resultados

Fuente: Elaboración propia. (Leal N, Martinez M, \& Bacre D 2021)

antes mencionados.

Otro aspecto importante en la pandemia fue el 
impacto económico que tuvieron las empresas, preguntamos qué medidas tomaron para amortiguar la crisis económica en sus organizaciones que impactaron directamente en el recurso humano.

En los resultados que obtuvimos nos damos cuenta de que algunas empresas tomaron diversas medidas para superar la crisis económica y de nuestra muestra 9 de ellas no tomaron ninguna acción debido a que no fueron afectadas como el sector de la salud, algunas empresas con giro industrial $y$ comercios. En la Figura 3. Podemos observar que 16 organizaciones tuvieron reducción de jornada laboral, 13 empresas realizaron paros técnicos, 10 empresas tuvieron que realizar convenios para la reducción de prestaciones, 9 organizaciones recortaron su plantilla de personal, 8 empresas hicieron convenios para la reducción de sueldos.

Figura 3. Acciones en crisis económica COVID19

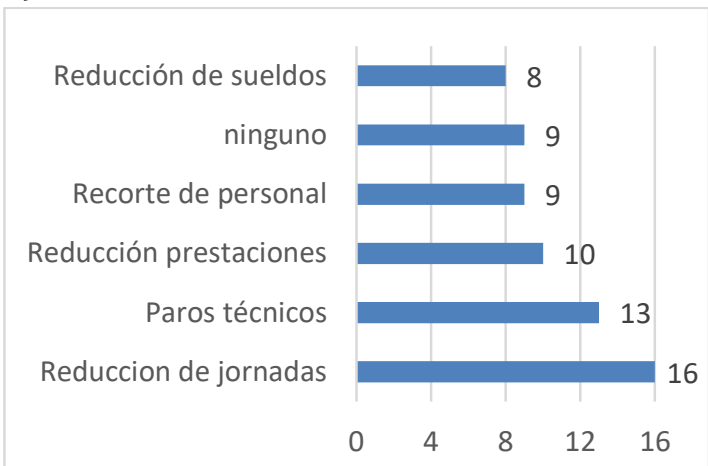

Fuente: Elaboración propia. (Leal N, Martínez M, \& Bacre D 2021) realizaron cambios organizacionales como:

- Reingeniería organizacional (rediseño de los procesos de la organización),

- Enriquecimiento de puestos (los empleados adquieren más responsabilidades y nuevas funciones),

- Rediseño de puestos de trabajo (fusión de puestos por cambios en el alcance del puesto).

El mayor reto al que se enfrentan la administración del recurso humano en esta pandemia es en asegurar la productividad de los empleados, como se presenta en la Tabla 1 y figura 4 , de nuestra muestra de 50 empresas 27 empresas coinciden que ha sido el reto más desafiante, el segundo reto es la comunicación con los empleados así lo consideran 16 empresas, el tercer un reto es la reducción de costos de nomina según 13 empresas, el cuarto reto son las jornadas de trabajo, el quinto es la capacitación 9 empresas así lo consideran, el sexto reto es la contratación temporal de personal según 8 empresas, el noveno reto es asegurar el cumplimiento de las normativas establecidas por organismos gubernamentales y el ausentismo, el decimo reto es la rotación de personal según 5 empresas.

Tabla 1. Mayores Retos en la Administración del Recurso Humano durante la pandemia Fuente: Elaboración propia. (Leal N, Martinez M, \& Bacre D 2021)

Para soportar estos cambios 31 empresas

\begin{tabular}{|c|c|}
\hline $\begin{array}{c}\text { ¿Cuáles consideras que han sido los mayores retos en la administración del recurso humano para } \\
\text { tu empresa durante esta pandemia? }\end{array}$ & \# empresas \\
\hline \hline Asegurar la productividad de los empleados & 27 \\
\hline Comunicación con los empleados & 16 \\
\hline Reducción de costos de nomina & 13 \\
\hline Jornadas de trabajo & 9 \\
\hline Capacitación & 9 \\
\hline Contratación de personal temporal & 8 \\
\hline Asegurar el cumpliendo de las normativas establecidas por los organismos gubernamentales & 7 \\
\hline Ausentismo & 7 \\
\hline Rotación, & 5 \\
\hline
\end{tabular}


Figura 4. Mayores Retos en la Administración del Bęqurso Humano durante la pandemia

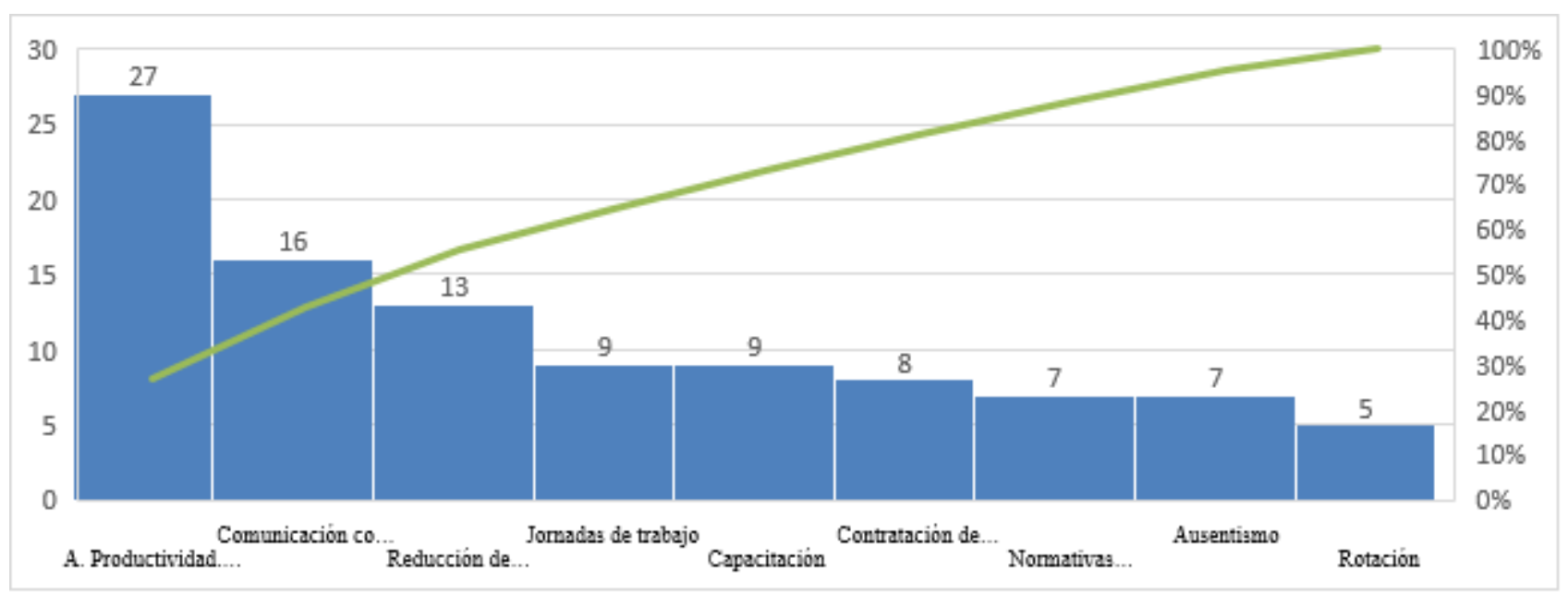

Fuente: Elaboración propia. (Leal N, Martinez M, \& Bacre D 2021)

Un eje importante de esta investigación es el Bienestar y salud del trabajador, en la encuesta se preguntó si modificaron las medidas de seguridad y equipo de protección la respuesta que obtuvimos fue que un $92 \%$ de nuestra muestra (46 empresas) si lo hicieron.

También preguntamos qué prácticas se están implementando para el bienestar del trabajador, se muestran los resultados en la tabla 2 y figura 5 .

Tabla 2. Implementación de prácticas para el bienestar del trabajador

\begin{tabular}{||c|c||}
\hline $\begin{array}{c}\text { ¿Prácticas que ha implementado tu } \\
\text { empresa para el bienestar del } \\
\text { trabajador en esta pandemia? }\end{array}$ & \# empresas \\
\hline \hline Medidas sanitarias & 28 \\
\hline Ninguno & 14 \\
\hline Facilitar ayuda psicológica & 9 \\
\hline $\begin{array}{c}\text { Compartir tips para motivar a nuestros } \\
\text { empleados }\end{array}$ & 6 \\
\hline Flexibilidad con los empleados & 6 \\
\hline $\begin{array}{c}\text { Reuniones virtuales (integración, } \\
\text { sociales, juegos) }\end{array}$ & 5 \\
\hline $\begin{array}{c}\text { Pruebas de Covid-19 para familiares en } \\
\text { caso de presentar síntomas }\end{array}$ & 5 \\
\hline Webinars sobre temas de interés & 4 \\
\hline Citas domiciliarias & 2 \\
\hline Línea telefónica de ayuda & 1 \\
\hline \hline
\end{tabular}

Figura 5. Implementación de prácticas para el bienestar del trabajador 
Fuente: Elaboración propia. (Leal N, Martínez M, \& Bacre D 2021)

\section{CONCLUSIONES}

La Pandemia Covid-19 ha obligado al mundo ajustarse a cambios. Y las organizaciones también han tenido que adaptarse a estos cambios y preparar a sus trabajadores para los nuevos retos, lo que demanda un sistema de gestión eficiente de recursos humanos para poder ser agentes de cambio.

También nos dimos cuenta de que las empresas cambiaron su estructura de trabajo completamente, tuvieron que ser flexibles para evitar contagios. Así mismo existen trabajos que lamentablemente no se podían realizar a distancia y surgió la idea de turnar a los trabajadores para que no todos se presentaran simultáneamente con el propósito de tener "sana distancia" durante su horario laboral.

Los tres principales retos a los que se enfrenta la administración del recurso humano en esta pandemia, en primer lugar es asegurar la productividad de los empleados, que se cumplan los objetivos de productividad en los puestos de trabajo, sin importar los horarios de trabajo, condiciones laborales, nuevos entornos, tecnología, etc. ahora bien si conjuntamos la variable que se trabaja desde casa (teletrabajo), se torna más retador para las organizaciones debido a los muchos distractores que tenemos en el hogar.

El segundo reto, la comunicación con los empleados, en estos tiempos nos confirma la importancia de la comunicación interna en la organización, construir una comunidad laboral a distancia en que los mensajes y los medios a utilizar dependen de los trabajadores, saber que ellos son el eje central para facilitar el desempeño de sus funciones a distancia a través de la credibilidad y la confianza en los mensajes que trasmiten son determinantes en la productividad de la organización.

La reducción de costos de nómina el tercer reto fue la solución que algunas empresas vieron para reducir sus costos y permanecer en el mercado en este tiempo de incertidumbre económica la preocupación de la organización es que el empleado busque nuevas oportunidades laborales y cambie de empleo. Un elemento importante en este reto es la solidaridad de los trabajadores al firmar sus convenios para las reducciones de prestaciones o salarios.

En los resultados podemos observar que las practicas implementadas para el bienestar de los trabajadores no están relacionadas con la remuneración sino con el campo de la salud ocupacional que está asociada a la seguridad y salud en el trabajo, 7 de las 9 actividades que se implementaron están dirigidas al cuidado del bienestar emocional de los trabajadores:

- Facilitar ayuda psicológica

- Compartir tips para motivar a nuestros empleados,

- Flexibilidad con los empleados,

- Realizar reuniones virtuales de integración, para socializar, hacer juegos o actividades de entretenimiento,

- Webinars sobre temas de interés,

- Citas domiciliarias como atención y seguimiento a los trabajadores en algunas ocasiones estas visitas han ayudado a identificar necesidades o situaciones adversas que viven los trabajadores,

- Línea telefónica de ayuda.

Este resultado nos da campo para una nueva investigación acerca del bienestar emocional en las empresas.

Es también importante mencionar cómo los retos que se identificaron de la administración de recursos humanos en la pandemia algunos prevalecerán en la nueva "normalidad". 


\section{REFERENCIAS}

Artículo científico

Brooks, S., Webster, R., Smith, L., Woodland, L., Wesley, S., \& Greenberg, N. (2020, Febrero 26). The psychological impact of quarantine and how to reduce it.

Castellanos, D. M. (2020, junio 7). Retos empresariales tras el Coronavirus COVID 19. Bogotá. Peiró, J., \& Soler, A. (2020). El impulso al teletrabajo durante el COVID-19 y retos que plantea. Valencia, España.

Baruch, Y. (2001). The Status of Research on Teleworking and an Agenda for Future Research. International Journal of Managment Reviews, 3(2), 113-129.

\section{Libro impreso}

Dessler, G. y Varela R, (2011) Administración de recursos humanos Enfoque latinoamericano 5ta ed. PEARSON. 
Werther W. \& Davis K. (2008) Administración de recursos humanos El capital humano de las empresas 6ta ed. McGraw-Hill

Informes y reportes gubernamentales, institucionales o empresariales

Diario Oficial de la Federación. (2020, mayo 29). Acuerdo por el que se establecen los

Lineamientos Técnicos Específicos para la Reapertura de las Actividades:

http://dof.gob.mx/nota_detalle.php?codigo $=5594138 \&$ fecha $=29 / 05 / 2020$

Ley Federal del Trabajo. (2019). Artículo 51. Retrieved from

https://www.gob.mx/cms/uploads/attachment/file/156203/1044_Ley_Federal_del_Trabajo.pdf

Secretaría del Trabajo y Previsión Social. (2020). En marzo se perdieron más de 130 mil empleos formales ante los efectos del COVID-19. Ciudad de México.

https://www.gob.mx/shcp\%7Cgacetaeconomica/articulos/en-marzo-se-perdieron-mas-de-130-mil-

empleos-ante-los-efectos-del-covid-19

Organización mundial de la Salud. (2020). Preguntas y respuestas sobre la enfermedad por

coronavirus (COVID-19). Retrieved from OMS

https://www.who.int/es/emergencies/diseases/novel-coronavirus-2019/question-and-answers-hub/q-

a-detail/coronavirus-disease-covid-19

Organización Internacional del Trabajo. (2020). COVID19: Como están actuando los países.

Retrieved from OIT:

https://www.ilo.org/global/topics/coronavirus/impacts-and-responses/WCMS_739405/lang--

es/index.htm

Organización Mundial de la Salud. (2010, febrero 24). ¿Qué es una pandemia? Retrieved from OMS:

https://www.who.int/csr/disease/swineflu/frequently_asked_questions/pandemic/es/

Organización Mundial de la Salud. (2020, mayo 10). Consideraciones a las medidas de salud

públicas y sociales en el lugar de trabajo en el contexto del COVID-19. Retrieved from OMS:

https://apps.who.int/iris/bitstream/handle/10665/332084/WHO-2019-nCoV- 